\title{
Structural and thermodynamic signatures that define pseudotriloop RNA hairpins
}

\author{
RAMON VAN DER WERF, ${ }^{1,2,3}$ SYBREN S. WIJMENGA, ${ }^{2}$ HANS A. HEUS, ${ }^{2}$ and RENÉ C.L. OLSTHOORN ${ }^{1,4}$ \\ ${ }^{1}$ Leiden Institute of Chemistry, University of Leiden, 2333 CC Leiden, The Netherlands \\ ${ }^{2}$ Institute for Molecules and Materials, Radboud University Nijmegen, 6525 AJ Nijmegen, The Netherlands \\ ${ }^{3}$ Department of Radiology, Erasmus Medical Centre, 3015 CE Rotterdam, The Netherlands
}

\begin{abstract}
Pseudotriloop (PTL) structures in RNAs have been recognized as essential elements in RNA folding and recognition of proteins. PTL structures are derived from hexaloops by formation of a cross-loop base pair leaving a triloop and $3^{\prime}$ bulged out residue. Despite their common presence and functional importance, insufficient structural and thermodynamic data are available that can be used to predict formation of PTLs from sequence alone. Using NMR spectroscopy and UV-melting data we established factors that contribute to the formation and stability of PTL structures derived from hepatitis B virus and human foamy virus. The NMR data show that, besides the cross-loop base pair, also a $3^{\prime}$ pyrimidine bulge and a G-C loop-closing base pair are primary determinants of PTL formation. By changing the $\mathrm{G}-\mathrm{C}$ closing base pair into $\mathrm{C}-\mathrm{G}$, the PTL switches into a hexaloop. Comparison of these rules with regular triloop hairpins and PTLs from other sources is discussed as well as the conservation of a PTL in human foamy virus and other spumaretroviruses.
\end{abstract}

Keywords: foamy virus; HBV; NMR; RNA hairpin; UV melting

\section{INTRODUCTION}

Pseudotriloop (PTL) hairpins (Haasnoot et al. 2002) or lonepair triloop hairpins (Lee et al. 2003) are common, albeit rarely studied, structures in RNA (Addess et al. 1997; Flodell et al. 2002, 2006; Kulinski et al. 2003; Welting et al. 2008). A PTL is proposed to form by creating a cross-loop base pair in an RNA hexaloop such that a triloop is created and the $3^{\prime}$ sixth loop base is bulged out (Fig. 1, tHBV). The term "pseudo" refers to the fact that in some cases a regular triloop can fulfill the same function or performs even better (Haasnoot et al. 2002). To support this view, it was recently demonstrated that the PTL and triloop promoter hairpins of brome mosaic virus (BMV) adopt an almost identical structure, although the latter one has higher thermodynamic stability (Skov et al. 2012). It has been shown that PTLs are recognition sites for proteins (Haasnoot et al. 2000, 2002, 2003): Disruption of the cross-loop base pair diminishes or sometimes even abolishes protein binding, and thus affects functioning of the RNA.

RNA loop structures with the potential to form PTLs are found in a variety of sequences, e.g., BMV (Haasnoot et al. 2000, 2002), domain IIId of the internal ribosomal entry site (IRES) of hepatitis C virus (Klinck et al. 2000; Lukavsky

\footnotetext{
${ }^{4}$ Corresponding author

E-mail olsthoor@chem.leidenuniv.nl

Article published online ahead of print. Article and publication date are at http://www.rnajournal.org/cgi/doi/10.1261/rna.039636.113.
}

et al. 2000, 2003), RNAse MRP P3 domain (Welting et al. 2008), HIV-1 TAR (Critchley et al. 1993; Kulinski et al. 2003), the apical loop of hepatitis B virus (HBV) $\varepsilon$ domain (Flodell et al. 2002, 2006), and iron responsive element (IRE) (Sierzputowska et al. 1995; Liang and Hall 1996; Hall and Williams 2004). The BMV, HBV, HCV, and IRE PTL structures have been established experimentally (Addess et al. 1997; Lukavsky et al. 2000; Flodell et al. 2002, 2006; Skov et al. 2012). The PTL of HIV is still debated as functional data suggest its formation, but the typical cross-loop base pair has not been observed directly by high-resolution structural studies yet (Jaeger and Tinoco 1993; Aboul-Ela et al. 1996; Kulinski et al. 2003; Dethoff et al. 2008, 2012).

Although the existence of PTLs has been proven, no consensus has been reached as to which sequence elements are necessary to form PTLs. Secondary structure prediction programs are unable to predict PTL structures due to lack of appropriate energy parameters and in general predict a hexaloop structure, including the proven PTLs of IRE and HBV $\varepsilon$. Here, we investigated the presence of PTL structures in a series of RNA hairpins based on $\mathrm{HBV} \varepsilon$, human foamy virus (HFV), and HIV PTLs by means of NMR and correlated these

C 2013 van der Werf et al. This article is distributed exclusively by the RNA Society for the first 12 months after the full-issue publication date (see http:// rnajournal.cshlp.org/site/misc/terms.xhtml). After 12 months, it is available under a Creative Commons License (Attribution-NonCommercial 3.0 Unported), as described at http://creativecommons.org/licenses/by-nc/3.0/. 


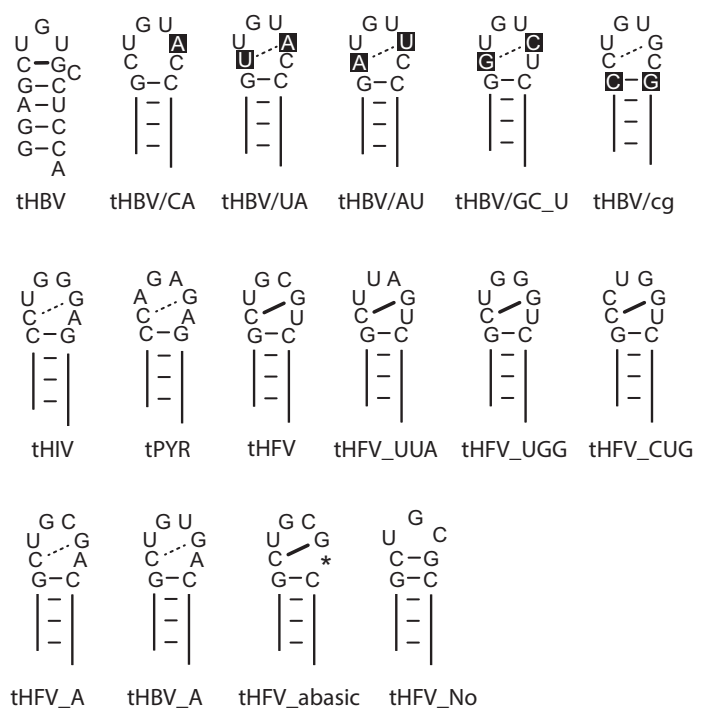

FIGURE 1. Secondary structure models of RNA hairpins used in this study. A putative cross-loop base pair is indicated by a dashed line or by a thick line in those constructs that showed indications of a PTL by NMR. The asterisk in tHFV_abasic denotes the position of the abasic residue.

with their thermodynamic stabilities using UV-melting spectroscopy. The data provide insight into the sequence requirements for PTL formation and stability, from which a consensus structure can be derived making their prediction from sequence more reliable.

\section{RESULTS}

For this study we collected a family of established and putative PTLs covering a wide sequence space. We investigated the existence and thermodynamic stability of several PTL structures derived from various viral sources, including the HBV $\varepsilon$ and HIV-1 TAR loops, and two postulated candidate PTLs: a stem-loop from a spumaretrovirus (HFV) and a bacterial hairpin involved in regulation of pyrimidine synthesis, pyrR (Haasnoot et al. 2003).

One-dimensional (1D) imino ${ }^{1} \mathrm{H}$ NMR spectra were recorded to validate that a PTL was formed. Since the primary goal was to observe presence or absence of PTLs by NMR, we transplanted PTL candidates onto a 4-bp stem with good chemical shift dispersion and known chemical shift values, allowing for unambiguous assignment of imino proton resonances. As test case we used the well-defined PTL motif of the HBV $\varepsilon$ domain (Flodell et al. 2002, 2006). The engineered construct-denoted tHBV is depicted in Figure 1 (the prefix " $t$ " indicates the designed base stem). The cross-loop CG base pair of the HBV PTL in its original sequence context shows a broadened imino proton resonance at $\sim 13 \mathrm{ppm}$ (Flodell et al. 2002); indeed at this value we observed this broadened resonance line for the cross-loop base pair of tHBV (Fig. 2). When the cross-loop base pair was disrupted (tHBV/CA), more resonances with larger line width and less intensity than the signals of the stem base pairs appeared (Fig. 2). This is possibly due to formation of dimers resulting from loop destabilization and introducing a palindromic loop sequence GUAC. Restoring the cross-loop base pair to UA (tHBV/UA) led to the expected stem resonances but also showed additional resonance lines with low intensity, indicating possible dimer formation (Fig. 2). Replacing the crossloop base pair by AU (tHBV/AU) led to the expected stem resonances but showed no indication of a cross-loop imino proton. Likewise, replacing the CG cross-loop base pair by GC (tHBV/GC_U) led to disappearance of the imino proton at 13 ppm (Fig. 2). Note that the C-bulge was changed to a $U$ to prevent the formation of an alternative G5-C10 base pair in this construct (Fig. 1). Remarkably, inverting the loop-closing GC base pair (tHBV/cg) into CG resulted in the disappearance of the cross-loop resonance as well (Fig. 2).

Having validated our approach for identifying the crossloop base pair by NMR, we next focused on PTLs derived from the HIV-1 TAR hairpin (tHIV), a HFV hairpin (tHFV), and the bacterial pyrR hairpin (tPYR). These hairpins all share a CG cross-loop base pair and have a CG or GC loop-closing base pair, while the HIV-1 TAR and pyrR hairpin share an A-bulge. The tHIV and tPYR loop sequences did not give rise to the characteristic cross-loop resonance at $\sim 13 \mathrm{ppm}$.

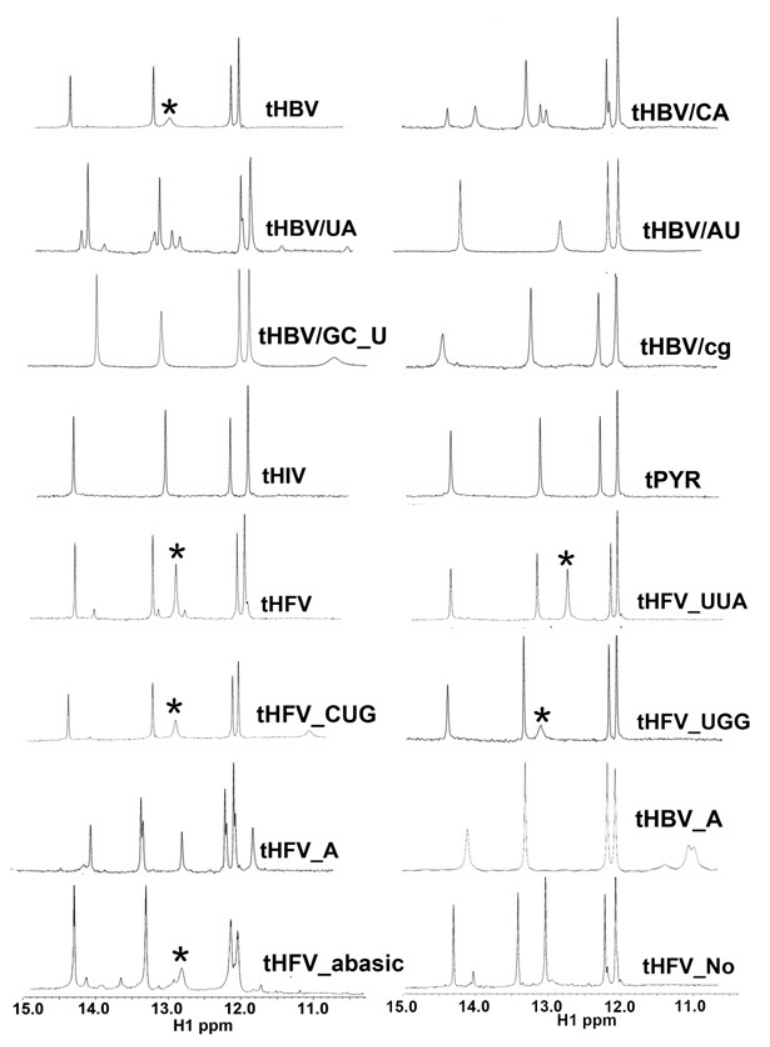

FIGURE 2. 1D imino proton spectra of RNA samples depicted in Figure 1. The asterisk $\left({ }^{*}\right)$ denotes the resonance of the cross-loop base pair. 
The imino spectra of tHIV and tPYR are almost identical and very similar to that of $\mathrm{tHBV} / \mathrm{cg}$, indicating structural similarity of the stem-loop junction. Possibly, common structural features induced by the CG closing base pair prevent formation or detection of a stable PTL.

The foamy virus hairpin (tHFV) did show all expected imino proton resonances, including an additional sharp and strong resonance at $12.8 \mathrm{ppm}$ for the cross-loop CG base pair. The cross-loop CG base pair in this context is also sufficiently stable to generate a cross-peak in the $2 \mathrm{D}\left({ }^{1} \mathrm{H},{ }^{1} \mathrm{H}\right)$ NOESY spectrum, allowing complete resonance assignment from a sequential walk (Fig. 3).

The intensity of the cross-loop resonance in the tHFV spectrum compared with that of tHBV is remarkable considering the single pyrimidine difference in the triloop sequences. This prompted us to further investigate the effect of nucleotide composition of the triloop on PTL formation: tHFV_CUG (tHFV with shuffled UGC triloop), tHFVUGG (HFV with HIV-TAR triloop), tHFV-UUA (tHFV with UUA triloop). The UUA triloop was chosen, because according to Shu and Bevilacqua it is the most stable triloop closed by a CG base pair, followed by UGU (Shu and Bevilacqua 1999). Using temperature gradient electrophoresis Shu and Bevilacqua also selected CUG and UGC triloops closed by a CG base pair as stable hairpin elements, while hairpins with a UGG triloop were selected as unstable hairpins. The NMR spectrum of the UUA variant showed a sharp cross-loop imino proton resonance, while for CUG it was still visible albeit less pronounced and for UGG even less. This suggests that from a structural point of view PTLs with a cross-loop CG base pair follow the same stability ranking as triloops with the exception of tHFV_UGC (Shu and Bevilacqua 1999).

The inability to detect a PTL for tPYR and tHIV could also be a consequence of the presence of the A-bulge as opposed to

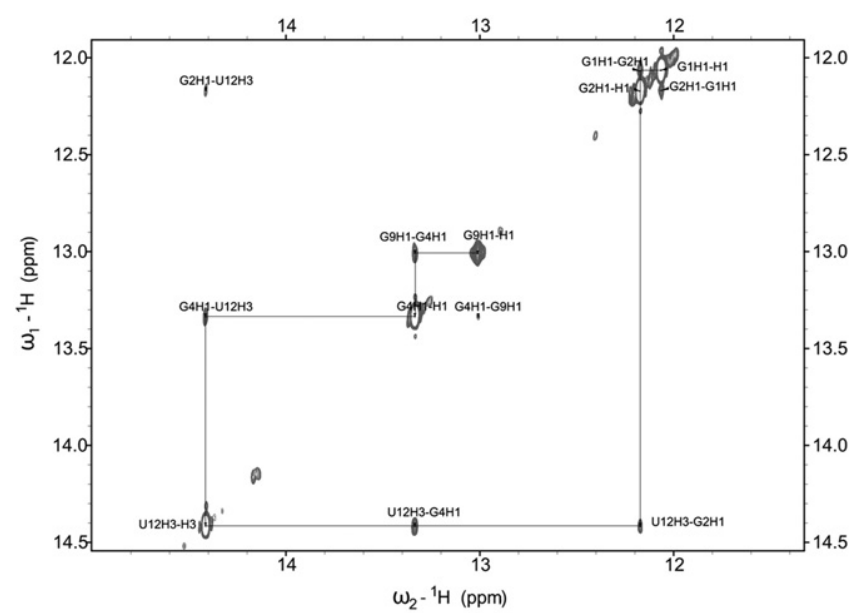

FIGURE 3. ${ }^{1} \mathrm{H}-{ }^{1} \mathrm{H}$ NOESY of the tHFV hairpin, showing the imino proton region (recorded at $2^{\circ} \mathrm{C}, 300 \mathrm{msec}$ mixing time). The diagonal peak G9H1-G4H1 correlates the base stem with the cross-loop base pair in the PTL structure. the U- or C-bulge in the PTLs of HBV and HFV, respectively. For this reason samples were prepared in which the bulge of tHFV was changed to A (tHFV_A), removed (tHFV_No), or replaced by a ribose only (tHFV_abasic). The $1 \mathrm{D}$ imino spectrum of tHFV_A showed many apparent doublets indicating a large fraction of dimers (Fig. 2). Also the additional broad peak at $11.5 \mathrm{ppm}$ that might originate from a GU base pair agrees with the presence of a self-complementary dimer or kissing loop interaction (5'-UGCG-3'/3'-GCGU-5'). Apparently, introducing an A-bulge in this loop context disfavors PTL formation. This was confirmed by changing the C-bulge of tHBV into A (tHBV_A), which resulted in disappearance of the cross-loop imino resonance (Fig. 2). Removing the base (tHFV_abasic) has no effect on PTL formation as the characteristic imino proton remains clearly visible. These observations lead to the conclusion that the reduced stacking properties of a pyrimidine or an abasic bulge favor PTL formation. The NMR spectrum of tHFV_No showed the expected five resonances with the CG loop-closing and penultimate base pairs occupying nearly the same chemical shift positions as the CG cross-loop and loop-closing base pairs in tHFV. This illustrates similar stacking interactions of the triloop on the CG base pairs in both cases, suggesting similar global structures.

\section{UV-melting studies}

Having determined key structural signatures of PTLs by NMR, we next ran UV-melting curves of the samples to correlate these with thermodynamic parameters. First UV-melting curves were run at different concentrations to determine if the RNAs were in the monomeric or dimer state. Nearly all sequences showed a single melting temperature between $65^{\circ} \mathrm{C}$ and $80^{\circ} \mathrm{C}$ independent of RNA concentration, demonstrating a uni-molecular folding process (Table 1). Some bulge variants of tHFV (tHFV_A, tHFV_No, and tHFV abasic) showed two melting transitions, i.e., a major transition at the typical high temperature range of $70^{\circ} \mathrm{C}-80^{\circ} \mathrm{C}$ corresponding to hairpin unfolding and a minor transition at a much lower temperature, between $30^{\circ} \mathrm{C}$ and $45^{\circ} \mathrm{C}$ (data not shown). Of these sequences only the lower melting temperature of tHFV_abasic was dependent on RNA concentration.

Comparison of the $\Delta G^{\circ}{ }_{37}$ values of tHBV and tHBV/CA indicated that the cross-loop CG base pair stabilizes loop folding by contributing $-1.6 \mathrm{kcal} / \mathrm{mol}$ to hairpin stability and that a UA cross-loop base pair also confers stability, albeit insignificant $(0.1 \mathrm{kcal} / \mathrm{mol})$ (Table 1$)$. Reverting the CG cross-loop base pair into GC destabilizes the tHBV loop by $0.6 \mathrm{kcal} / \mathrm{mol}$. Formation of the PTL in the tHFV sequence, showing a clear imino resonance of the cross-loop GC base pair, also correlates with stability, showing a $\Delta G^{\circ}{ }_{37}$ of $-6.5 \mathrm{kcal} / \mathrm{mol}$.

Remarkably, $\Delta G^{\circ}{ }_{37}$ of $\mathrm{tHBV} / \mathrm{cg}$ is identical to that of tHBV even though the NMR spectrum did not show 
TABLE 1. Thermodynamic parameters of hairpin formation

\begin{tabular}{lcccc}
\hline RNA & $\operatorname{Tm}\left({ }^{\circ} \mathrm{C}\right)$ & $\Delta \mathrm{G}^{\circ}{ }_{37}\left(\mathrm{kcal} \mathrm{mol}^{-1}\right)$ & $\Delta H^{\circ}\left(\mathrm{kcal} \mathrm{mol}^{-1}\right)$ & $\Delta S^{\circ}\left(\mathrm{cal} \mathrm{mol}^{-1} \mathrm{~K}^{-1}\right)$ \\
\hline tHBV $^{\mathrm{a}}$ & $75.7 \pm 0.7$ & $-5.7 \pm 0.4$ & $-52.2 \pm 4.5$ & $-149.7 \pm 13.2$ \\
tHBV/CA & $64.5 \pm 0.6$ & $-4.1 \pm 0.4$ & $-51.5 \pm 4.8$ & $-152.7 \pm 14.1$ \\
tHBV/UA & $67.3 \pm 0.7$ & $-4.2 \pm 0.4$ & $-48.3 \pm 4.6$ & $-141.8 \pm 13.7$ \\
tHBV/cg & $77.0 \pm 1.0$ & $-5.7 \pm 0.3$ & $-50.3 \pm 2.3$ & $-144.0 \pm 6.5$ \\
tHBV/AU & $64.0 \pm 0.9$ & $-4.4 \pm 0.4$ & $-54.7 \pm 6.4$ & $-162.2 \pm 19.7$ \\
tHBV/GC_U & $67.7 \pm 1.6$ & $-5.1 \pm 0.5$ & $-56.6 \pm 3.2$ & $-166.2 \pm 8.9$ \\
tHIV & $76.6 \pm 0.5$ & $-6.2 \pm 0.4$ & $-56.6 \pm 5.3$ & $-162.6 \pm 15.8$ \\
tPYR & $77.7 \pm 0.4$ & $-6.6 \pm 0.6$ & $-57.0 \pm 3.8$ & $-162.7 \pm 10.9$ \\
tHFV & $76.3 \pm 0.5$ & $-6.5 \pm 0.7$ & $-58.8 \pm 6.9$ & $-167.3 \pm 20.2$ \\
tHFV_CUG & $76.8 \pm 0.5$ & $-6.9 \pm 0.6$ & $-60.8 \pm 4.9$ & $-173.9 \pm 14.0$ \\
tHFV_UUA & $78.2 \pm 0.7$ & $-7.0 \pm 0.7$ & $-60.1 \pm 6.1$ & $-171.2 \pm 17.3$ \\
tHFV_UGG & $76.3 \pm 0.7$ & $-6.0 \pm 0.9$ & $-54.2 \pm 8.6$ & $-155.5 \pm 25.5$ \\
tHFV_A & $73.4 \pm 1.0$ & $-6.6 \pm 0.4$ & $-64.0 \pm 6.7$ & $-185.1 \pm 19.9$ \\
tHBV_A $^{a}$ & $73.4 \pm 0.5$ & $-6.0 \pm 0.4$ & $-58.9 \pm 4.2$ & $-171.2 \pm 18.5$ \\
tHFV_No $^{\text {a }}$ & $78.2 \pm 0.7$ & $-7.0 \pm 0.7$ & $-60.8 \pm 6.1$ & $-171.2 \pm 17.3$ \\
tHFV_abasic & $77.0 \pm 0.6$ & $-8.4 \pm 1.1$ & $-74.3 \pm 11.0$ & $-212.6 \pm 31.7$ \\
\hline
\end{tabular}

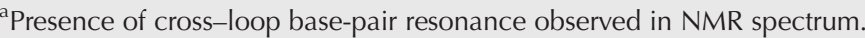

contrast to tHFV_A its NMR spectrum was not drastically changed, neither did its UV-melting curves show any anomalies. These data indicate a negative contribution of a $3^{\prime}$ bulge on PTL formation, which is least for an abasic residue or pyrimidine.

\section{Non-denaturing gel electrophoresis}

To obtain further indication of the monomeric behavior of the sequences and possible dimer formation, all samples were run on non-denaturing $15 \%$ polyacrylamide gels. This experiment was done with pretreatment of the samples in two ways, i.e., (1) by heating the sample to $95^{\circ} \mathrm{C}$ and subsequent snap-cool on ice, and (2) by slowly heating the samples to $95^{\circ} \mathrm{C}$ and subsequent cool-down

evidence for the presence of a cross-loop CG base pair for tHBV/cg. Also the other sequences with loop-closing CG base pair, tHIV and tPYR, showed comparable low $\Delta G^{\circ}{ }_{37} \mathrm{~s}$ ranging from -6.2 to $-6.6 \mathrm{kcal} / \mathrm{mol}$, but lacked a crossloop base pair. Apparently the closing CG base pair in these cases stabilizes hexaloop formation as shown before (Serra et al. 1993) and in triloops (Shu and Bevilacqua 1999; Thulasi et al. 2010) and tetraloops (Antao et al. 1991; Antao and Tinoco 1992; Blose et al. 2009) but counteracts formation of a PTL.

Thermodynamic stabilities of the different loop versions of tHFV followed the signal intensity of the cross-loop base pair in the NMR spectra: UUA $>$ CUG $>$ UGC $($ tHFV $)>$ UGG (Table 1), showing a clear correlation between structure and thermodynamic stability. Altogether the NMR and thermodynamic data indicate that the presence of a cross-loop base pair, combined with a closing GC base pair, is necessary to form a stable PTL.

Finally, we investigated the influence of the $3^{\prime}$ bulge, since the NMR data indicated a positive effect of a $3^{\prime}$ pyrimidine and negative effect of a $3^{\prime}$ adenine on PTL formation. Remarkably, tHFV_abasic was found to be the most stable PTL, with $1.5-2 \mathrm{kcal} / \mathrm{mol}$ higher stability than the regular PTLs. tHFV_No, which has a regular triloop, is the next stable hairpin, with $0.5 \mathrm{kcal} / \mathrm{mol}$ higher stability than the regular PTLs. $\Delta G^{\circ}{ }_{37}$ of tHFV_A is comparable to tHFV (with U-bulge) but showed complex NMR data and multiple transitions in the UV-melting curve, indicating multiple conformations. The stability of tHBV_A was also comparable to that of tHBV (with C-bulge), but in

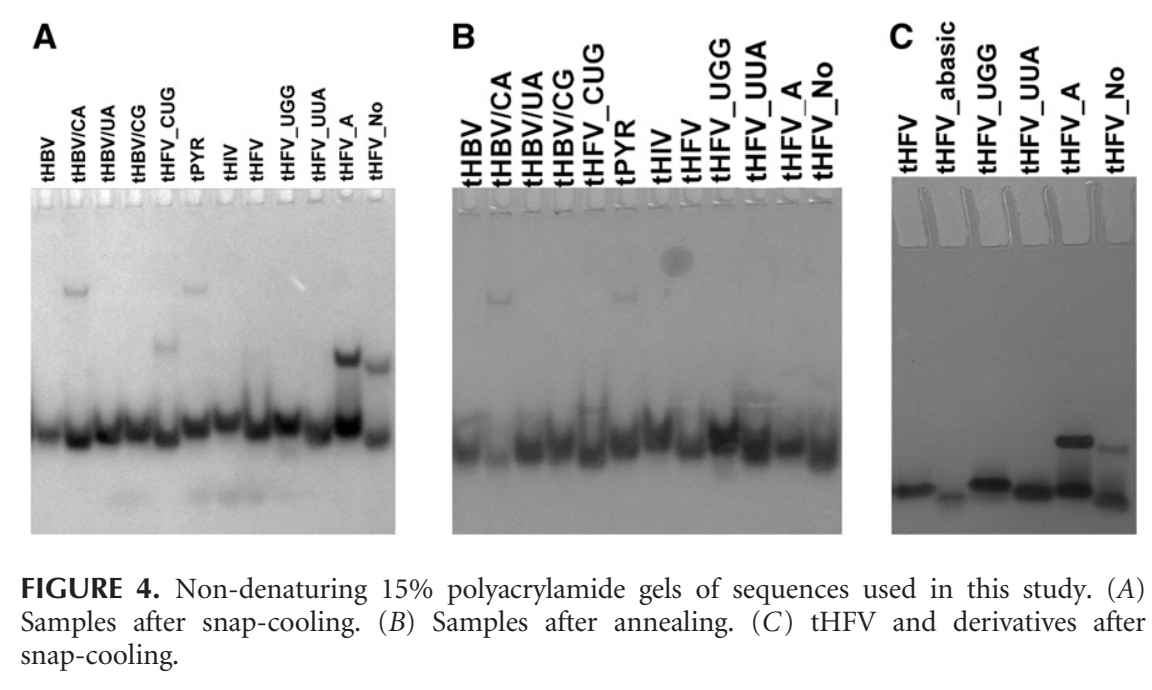

FIGURE 4. Non-denaturing $15 \%$ polyacrylamide gels of sequences used in this study. $(A)$ Samples after snap-cooling. (B) Samples after annealing. (C) tHFV and derivatives after snap-cooling. to $20^{\circ} \mathrm{C}$ at a rate of $1.0^{\circ} \mathrm{C} / \mathrm{min}$. All sequences showed one major fast-migrating band for both treatments (Fig. 4A,B). These fast migrating bands have comparable migration rates and most likely represent the monomeric hairpin conformer. After snap-cooling the RNA samples, tHBV/CA, tHFV_CUG, and tPYR showed a minor slower migrating band, and tHFV_A and tHFV_No showed a slower migrating band with considerable intensity (Fig. 4A,C), indicating possible dimer formation. tHBV_A migrated as a monomer (data not shown). Dimer formation agrees with observation of additional imino resonances in the 1D NMR spectra, of which the intensities follow the intensity of the additional slow migrating bands and observation of two melting transitions for tHFV_A and tHFV_No. Also, for these samples the transition at a lower temperature only occurred when melting a snap-cooled sample, but not in the reverse experiment when the heated sample was annealed. 


\section{DISCUSSION}

The aim of this work was to define rules for predicting PTL hairpins from sequence and to formulate a consensus structure. Using NMR and UV-melting studies we show that a consensus structure of PTLs can be proposed. A number of predicted PTL hairpins indeed adopt this conformation, while the absence of a PTL for some predicted PTLs can be explained by our proposed consensus structure.

We engineered a number of sequences representing wildtype HBV, PYR, HFV, and variants thereof, and by using 1D imino ${ }^{1} \mathrm{H}$ NMR spectroscopy, PTLs could be confirmed for the sequences tHFV, tHFV_CUG tHFV_UGC, tHFV_UGG, tHFV_UUA, tHFV_abasic, and tHBV. The tHFV PTL could further be confirmed by $2 \mathrm{D}\left({ }^{1} \mathrm{H},{ }^{1} \mathrm{H}\right)$ NOESY, which showed a clear cross-peak between the cross-loop CG and loop-closing GC base pairs.

For all established PTLs the resonance of the cross-loop base pair of the PTL was present in $1 \mathrm{D}^{1} \mathrm{H}$ NMR spectra at $\sim 13.0 \mathrm{ppm}$, a chemical shift position that was earlier observed for the cross-loop base pair of the PTL of the $\varepsilon$ domain apical loop of the hepatitis B virus (Flodell et al. 2002). The occurrence of this resonance is the criterion to establish PTL formation, since this is the only resonance that is not part of the base stem, and it is also the resonance indicative for PTL formation in HBV.

The identity of the cross-loop base pair strongly influences PTL formation; in most PTL samples investigated here, a CG cross-loop base pair is formed. Comparison of the thermodynamic stabilities of tHBV/UA, tHBV/AU, tHBV/GC_U, and tHBV (with CG) shows that a UA or AU base pair in the PTL destabilizes the hairpin structure by $\sim 1.5 \mathrm{kcal} / \mathrm{mol}$ and a GC base pair by $\sim 0.6 \mathrm{kcal} / \mathrm{mol}$, and from the NMR spectra a PTL structure cannot be unambiguously assigned to tHBV/UA, tHBV/AU, or tHBV/GC_U. Whether this is the case for all PTLs remains to be investigated. In the IRE PTL a UA cross-loop base pair is allowed and a UG cross-loop base pair is present in the HCV IRES domain IIId (Addess et al. 1997; Lukavsky et al. 2000). In these cases, however, the upper stem is further destabilized by additional AU or GU base pairs adjacent to the loop-closing base pair, which might also influence PTL formation. Disrupting the crossloop base-pair interaction increases $\Delta G^{\circ}$ by $0.6-1.6 \mathrm{kcal} /$ mol, showing PTL structures are thermodynamically more stable than their hexaloop counterparts (Table 1; Skov et al. 2012). In the case of HBV reported here this thermodynamic stability gain is largely an enthalpy contribution, suggesting base stacking is the primary stabilizing factor.

The 3' bulged out residue and loop-closing base pair are key factors that determine formation and stability of PTLs. The structures of tHFV and tHFV_abasic are similar, except for the presence of the bulged out uridine residue. The bulged out uridine, however, results in a profound $1.9-\mathrm{kcal} / \mathrm{mol}$ destabilization of the PTL, reflected in both $\Delta H$ and $\Delta S$, but dominated by $\Delta H$. This possibly reflects an enthalpic penalty by an extruding uridine base, which is absent in tHFV abasic. Introducing a bulged $\mathrm{A}$ instead of $\mathrm{U}$ does not lead to a difference in thermodynamic stability, but the NMR spectra are very different, corresponding to the absence of a PTL. Inverting the loop-closing GC base pair into CG, as in tHBV/cg and tHIV, also yields structures with comparable thermodynamic stabilities but leads to absence of a PTL as well.

The HIV-1 TAR hairpin has been studied using NMR by others before, but in these cases the CG cross-loop resonance was also not observed (Jaeger and Tinoco 1993; Aboul-Ela et al. 1996; Dethoff et al. 2008, 2012) although there is functional data to support its presence (Haasnoot et al. 2003; Kulinski et al. 2003). Our NMR data also showed no indication of a cross-loop base pair in tHIV and we ascribe this to the presence of an A-bulge and loop-closing CG base pair. tHIV thus harbors all ingredients that prevent detection of PTL conformation by NMR despite having a lower $\Delta G^{\circ}{ }_{37}$ than tHBV, whose PTL conformation is evident from the NMR data. Similarly the tPYR hairpin has a very low $\Delta G^{\circ}{ }_{37}$ but, due to the Abulge and CG loop-closing base pair, the cross-loop base pair was not detected by NMR. Possibly, tHIV and tPYR form hexaloops with low $\Delta G^{\circ}{ }_{37}$ due to enhanced stacking of the $3^{\prime}$ four purines in the tHIV (GGGA) and tPYR (GAGA) loops.

The identification of a PTL in tHFV is of considerable interest because of its strong sequence similarity to the HBV PTL and its resemblance to HIV-1 TAR in terms of genomic position and thus perhaps function. The full hairpins of these "retro"-viruses are shown in Figure 5. Comparison of these
FIGURE 5. Conservation of PTL structure in spumaretroviruses. Structure of retroviral HIV-1 TAR and HBV $\varepsilon$ hairpins is shown for comparison. Human foamy virus (GenBank accession number M54978), simian foamy virus (JQ867462), macaque simian foamy virus (JN801175), spider monkey foamy virus (EU010385), common marmoset foamy virus (GU356395), squirrel monkey foamy virus (GU356394), equine foamy virus (AF201902), feline foamy virus (KC292055), bovine foamy virus (JX307862). 
spumaretroviruses reveals that this hairpin and its PTL are strongly conserved among all known spumaretroviruses. The sequence homology to HBV suggests a common factor binding to the loop. The homology to HIV-TAR's genomic location, at the $5^{\prime}$ end of the mRNA, could point to a function in transcription-elongation. However, transcription activation by HFV-Taf depends on DNA sequences in the LTR and not on the nascent RNA like in HIV-1. The exact role of this conserved PTL hairpin in spumaretroviruses thus remains to be investigated.

\section{CONCLUSIONS}

Detection of the cross-loop base pair's resonance in NMR spectra is considered in this study as evidence for the formation of a PTL in hexaloop sequences. The intensity of this resonance in a number of different loop sequences correlates well with their measured thermodynamic stabilities. We conclude that PTL stability depends on (i) stacking energies between cross-loop and loop-closing base pairs, with CG and GC bp, respectively, resulting in the highest stability; (ii) identity of the $3^{\prime}$ bulge, with pyrimidines favoring and purines disfavoring PTL formation; (iii) sequence in the resulting triloop, where the same trend in stability is observed as for regular triloops (Shu and Bevilacqua 1999; Thulasi et al. 2010). The latter observation suggests that incorporation of a bonus for certain stable triloop motifs in RNA folding algorithms will likely result in the prediction of more PTLs as well. It should be noted, however, that certain natural RNA hairpins like HIV1-TAR, BMV, and IRE, whose PTL conformation has been shown to be required for their function, do not fulfill (all of) these criteria. Thus, depending on their function(s), certain RNAs may not have been endowed with the most stable PTL.

\section{MATERIALS AND METHODS}

\section{Sample preparation and non-denaturing PAGE}

RNA samples were purchased from IBA (Goettingen), except tHFV abasic, which was purchased from Dharmacon, and tHBV_A, tHBV/ $\mathrm{AU}$, and tHBV/GC_U, which were purchased from SigmaAldrich. Samples were dissolved in $450 \mu \mathrm{L} 0.1 \mathrm{M} \mathrm{Na}_{2} \mathrm{HPO}_{4} / \mathrm{NaH}_{2} \mathrm{PO}_{4}$ solution ( $\mathrm{pH}$ 6.7). For NMR studies $50 \mu \mathrm{L} \mathrm{D}_{2} \mathrm{O}$ was added for locking and referencing of the NMR spectra.

For analysis by non-denaturing gel electrophoresis, samples were prepared in two ways. Four microliters of each of the samples, diluted to a concentration of $0.08 \mathrm{mM}$, were either heated to $90^{\circ} \mathrm{C}$ and snap-cooled on iced water or heated to $95^{\circ} \mathrm{C}$ and slowly cooled to $20^{\circ} \mathrm{C}$ at a rate of $1{ }^{\circ} \mathrm{C} / \mathrm{min}$. Samples were put on a non-denaturing $15 \%$ polyacrylamide gel, and run for $3 \mathrm{~h}$ at $150 \mathrm{~V}$.

\section{${ }^{1} \mathrm{H}$ NMR experiments}

All spectra were recorded on a Varian Unity INOVA $800 \mathrm{MHz}$ spectrometer, equipped with a HCN triple resonance cryo probe.
Samples $(\sim 0.25 \mathrm{mM})$ were dissolved in $0.01 \mathrm{M} \mathrm{Na} \mathrm{NPO}_{4} /$ $\mathrm{NaH}_{2} \mathrm{PO}_{4}$ buffered solution ( $\mathrm{pH}$ 6.7), 90\% $\mathrm{H}_{2} \mathrm{O} / 10 \% \mathrm{D}_{2} \mathrm{O}$. For each of the samples a series of $1 \mathrm{D}$ imino ${ }^{1} \mathrm{H}$ NMR spectra were recorded over a temperature range from $2^{\circ} \mathrm{C}$ to $50^{\circ} \mathrm{C}$. $1 \mathrm{D}$ imino spectra shown in Figure 1 were recorded at $2^{\circ} \mathrm{C}$. Water suppression was achieved using WATERGATE (Saudek et al. 1994) and jump-return (Plateau and Gueron 1982; Hore 1983). Spectra were recorded with a spectral width of $20 \mathrm{kHz}$, recording 4000 points and accumulating 256 scans and a recycle delay of $1.5 \mathrm{sec} .2 \mathrm{D}\left({ }^{1} \mathrm{H},{ }^{1} \mathrm{H}\right)$ NOESY spectra were recorded at a temperature of $5^{\circ} \mathrm{C}$, with a mixing time of 300 $\mathrm{msec}$, employing the same water suppression techniques as in the $1 \mathrm{D}$ experiments. NOESYs were recorded with a spectral width of $20 \mathrm{kHz}$, recording 2400 points and accumulating 128 scans. In the indirect domain the spectral width was $17 \mathrm{kHz}$, and 375 increments were recorded with a recycle delay of $1.4 \mathrm{sec}$.

\section{UV-melting spectroscopy}

Samples were diluted to 5, 10,20, and $40 \mu \mathrm{g} / \mathrm{mL}$ in $0.1 \mathrm{M} \mathrm{Na}_{2} \mathrm{HPO}_{4} /$ $\mathrm{NaH}_{2} \mathrm{PO}_{4}$ buffered solution ( $\mathrm{pH}$ 6.7). The diluted samples were heated to $95^{\circ} \mathrm{C}$ for two minutes and snap-cooled on iced water. Melting profiles were recorded using a Varian Cary300 UV spectrometer. The UV absorbance at a wavelength of $260 \mathrm{~nm}$ was measured with a heating rate of $0.5^{\circ} \mathrm{C} / \mathrm{min}$ from 0.5 up to $95^{\circ} \mathrm{C}$, and subsequently cooled with the same rate from $95^{\circ} \mathrm{C}$ down to $0.5^{\circ} \mathrm{C}$.

\section{Analysis of UV-melting profiles}

First, recorded UV-data were corrected for baseline drift by fitting a straight line to a flat part of the baseline, and subtracting this line from the data. Next, the data were normalized by dividing all data by the maximum absorbance found in the profile. The normalized UV-melting curve was fitted against a sigmoid:

$$
A=\frac{a}{\left(1+e^{-b(T-c)}\right)}+f \cdot T+g
$$

where $A$ is the normalized absorbance and $T$ is the temperature. Parameters $a, b, c, f$, and $g$ are optimized with a nonlinear least square fitting procedure. The derivative of the fit was calculated numerically and has an approximate Gaussian shape, and the maximum value of this derivative occurs at the melting temperature $T_{\mathrm{m}}$. The error in $T_{\mathrm{m}}$ was determined as the standard deviation between a series of measurements at the reported concentrations.

Thermodynamic parameters were derived from the transition region of the melting curve. When assuming a monomer RNA strand that unfolds, the reciprocal temperature versus the mol fraction of unfolded RNA is a straight line, obeying (Puglisi and Tinoco 1989):

$$
\ln K=-\frac{\Delta H}{R} \cdot \frac{1}{T}+\frac{\Delta S}{R},
$$

where $K$ is the equilibrium constant between folded and unfolded state, $\Delta H$ is the enthalpy, $\Delta S$ the entropy, $R$ the gas constant, and $T$ the absolute temperature. The Gibbs-free energy of unfolding was calculated from the well-known relationship:

$$
\Delta G^{\circ}=\Delta H^{\circ}-T \Delta S^{\circ}
$$




\section{ACKNOWLEDGMENTS}

This research was funded by a VIDI grant from the Netherlands Organisation for Scientific Research awarded to R.C.L.O.

Received April 26, 2013; accepted September 20, 2013.

\section{REFERENCES}

Aboul-Ela F, Karn J, Varani G. 1996. Structure of HIV-1 TAR RNA in the absence of ligands reveals a novel conformation of the trinucleotide bulge. Nucleic Acids Res 24: 3974-3981.

Addess KJ, Basilion JP, Klausner RD, Rouault TA, Pardi A. 1997. Structure and dynamics of the iron responsive element RNA: Implications for binding of the RNA by iron regulatory binding proteins. J Mol Biol 274: 72-83.

Antao VP, Tinoco I Jr. 1992. Thermodynamic parameters for loop formation in RNA and DNA hairpin tetraloops. Nucleic Acids Res 20: 819-824.

Antao VP, Lai SY, Tinoco I Jr. 1991. A thermodynamic study of unusually stable RNA and DNA hairpins. Nucleic Acids Res 19: 59015905.

Blose JM, Proctor DJ, Veeraraghavan N, Misra VK, Bevilacqua PC. 2009. Contribution of the closing base pair to exceptional stability in RNA tetraloops: Roles for molecular mimicry and electrostatic factors. J Am Chem Soc 131: 8474-8484.

Critchley AD, Haneef I, Cousens DJ, Stockley PG. 1993. Modeling and solution structure probing of the HIV-l TAR stem-loop. J Mol Graph 11: 92-97.

Dethoff EA, Hansen AL, Musselman C, Watt ED, Andricioaei I, AlHashimi HM. 2008. Characterizing complex dynamics in the transactivation response element apical loop and motional correlations with the bulge by NMR, molecular dynamics, and mutagenesis. Biophys J 95: 3906-3915.

Dethoff EA, Petzold K, Chugh J, Casiano-Negroni A, Al-Hashimi HM. 2012. Visualizing transient low-populated structures of RNA. Nature 491: 724-728.

Flodell S, Schleucher J, Cromsigt JAMTC, Ippel H, Kidd-Ljunggren K, Wijmenga SS. 2002. The apical stem-loop of the hepatitis B virus encapsidation signal folds into a stable tri-loop with two underlying pyrimidine bulges. Nucleic Acids Res 30: 4803-4811.

Flodell S, Petersen M, Girard FC, Zdunek J, Kidd-Ljunggren K, Schleucher J, Wijmenga SS. 2006. Solution structure of the apical stem-loop of the human hepatitis B virus encapsidation signal. Nucleic Acids Res 34: 4449-4457.

Haasnoot PCJ, Brederode FT, Olsthoorn RCL, Bol JF. 2000. A conserved hairpin structure in Alfamovirus and Bromovirus subgenomic promoters is required for efficient RNA synthesis in vitro. RNA 6: 708-716.

Haasnoot PCJ, Olsthoorn RCL, Bol JF. 2002. The Brome mosaic virus subgenomic promoter hairpin is structurally similar to the iron-responsive element and functionally equivalent to the minus-strand core promoter stem-loop C. RNA 8: 110-122.

Haasnoot PCJ, Bol JF, Olsthoorn RCL. 2003. A plant virus replication system to assay the formation of RNA pseudotriloop motifs in RNA-protein interactions. Proc Natl Acad Sci 100: 1259612600 .

Hall KB, Williams DJ. 2004. Dynamics of the IRE RNA hairpin loop probed by 2 -aminopurine fluorescence and stochastic dynamics simulations. RNA 10: 34-47.

Hore PJ. 1983. Solvent suppression in Fourier transform nuclear magnetic resonance. J Magn Reson 55: 283-300.

Jaeger JA, Tinoco I Jr. 1993. An NMR study of the HIV-1 TAR element hairpin. Biochemistry 32: 12522-12530.

Klinck R, Westhof E, Walker S, Afshar M, Collier A, Aboul-ela F. 2000. A potential RNA drug target in the hepatitis $\mathrm{C}$ virus internal ribosomal entry site. RNA 6: 1423-1431.

Kulinski T, Olejniczak M, Huthoff H, Bielecki L, Pachulska-Wieczorerk K, Das AT, Berkhout B, Adamiak RW. 2003. The apical loop of the HIV-1 TAR RNA hairpin is stabilized by a cross-loop base pair. J Biol Chem 278:38892-38901.

Lee JC, Cannone JC, Gutell RR. 2003. The lonepair triloop: A new motif in RNA structure. J Mol Biol 325: 65-83.

Liang LG, Hall KB. 1996. A model of the iron responsive element RNA hairpin loop structure determined from NMR and thermodynamic data. Biochemistry 35: 13586-13596.

Lukavsky PJ, Otto GA, Lancaster AM, Sarnow P, Puglisi JD. 2000. Structures of two RNA domains essential for hepatitis $\mathrm{C}$ virus internal ribosome entry site function. Nat Struct Biol 7: 11051110.

Lukavsky PJ, Kim I, Otto GA, Puglisi JD. 2003. Structure of HCV IRES domain II determined by NMR. Nat Struct Biol 10: 1033-1038.

Plateau P, Gueron M. 1982. Exchangeable proton NMR without baseline distorsion, using new strong-pulse sequences. J Am Chem Soc 104: 7310-7311.

Puglisi JD, Tinoco I Jr. 1989. Absorbance melting curves of RNA. Methods Enzymol 180: 304-325.

Saudek V, Piotto M, Sklenar V. 1994. WATERGATE: Applications in homonuclear and heteronuclear nD NMR experiments. Bruker Report 140: 6-9.

Serra MJ, Lyttle MH, Axelson TJ, Schadt CA, Turner DH. 1993. RNA hairpin loop stability depends on closing base pair. Nucleic Acids Res 21: 3845-3849.

Shu ZY, Bevilacqua PC. 1999. Isolation and characterization of thermodynamically stable and unstable RNA hairpins from a triloop combinatorial library. Biochemistry 38: 15369-15379.

Sierzputowska H, McKenzie RA, Theil EC. 1995. The importance of a single $G$ in the hairpin loop of the iron responsive element (IRE) in ferritin mRNA for structure: An NMR spectroscopy study. Nucleic Acids Res 23: 146-153.

Skov J, Gaudin M, Podbevsek P, Olsthoorn RCL, Petersen M. 2012. The subgenomic promoter of brome mosaic virus folds into a stem-loop structure capped by a pseudo-triloop that is structurally similar to the triloop of the genomic promoter. RNA 18: 992-1000.

Thulasi P, Pandya LK, Znosko BM. 2010. Thermodynamic characterization of RNA triloops. Biochemistry 49: 9058-9062.

Welting TJM, Matijssen S, Peters FMA, van Doorn NL, Dekkers L, van Venrooij WJ, Heus HA, Bonafe L, Pruijn GJM. 2008. Cartilage-hair hypoplasia-associated mutations in the RNase MRP P3 domain affect RNA folding and ribonucleoprotein assembly. Biochim Biophys Acta 1783: 455-466. 

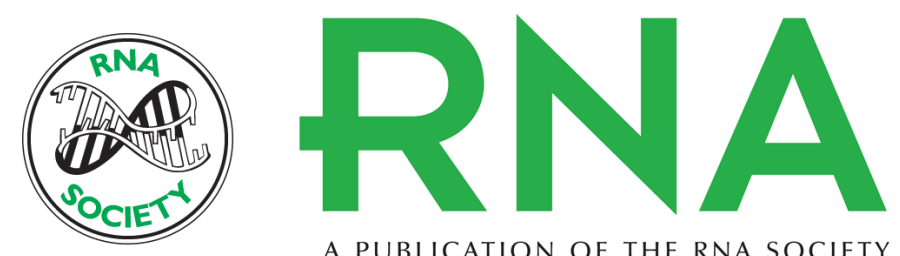

A PUBLICATION OF THE RNA SOCIETY

\section{Structural and thermodynamic signatures that define pseudotriloop RNA hairpins}

Ramon van der Werf, Sybren S. Wijmenga, Hans A. Heus, et al.

RNA 2013 19: 1833-1839 originally published online October 24, 2013

Access the most recent version at doi:10.1261/rna.039636.113

\section{References This article cites 31 articles, 7 of which can be accessed free at: http://rnajournal.cshlp.org/content/19/12/1833.full.html\#ref-list-1 \\ Creative This article is distributed exclusively by the RNA Society for the first 12 months after the Commons License full-issue publication date (see http://rnajournal.cshlp.org/site/misc/terms.xhtml). After 12 months, it is available under a Creative Commons License (Attribution-NonCommercial 3.0 Unported), as described at http://creativecommons.org/licenses/by-nc/3.0/.}

Email Alerting

Receive free email alerts when new articles cite this article - sign up in the box at the Service top right corner of the article or click here. 